\title{
A JUSTAPOSIÇÃO ORACIONAL EM DADOS DE AQUISIÇÃO DA ESCRITA
}

\section{Lúcia Regiane Lopes-Damasio*}

Resumo: Neste trabalho, assumo um modelo funcionalista de junção (RAIBLE, 2001), um entendimento da escrita como constitutivamente heterogênea e como modo de enunciação (CORRÊA, 2004) e uma concepção de aquisição da escrita que considera as tradições discursivas (KABATEK, 2006), com o intuito de lançar um olhar linguístico-discursivo para as construções paratáticas justapostas, em dados de aquisição da escrita. Os resultados apontam que, nos dados investigados, a mescla de tradições discursivas e as junções que ocorrem numa mesma tradição são recorrentemente empreendidas por justaposição, enquanto gesto que aponta, no espaço gráfico, para a situação concreta de enunciação.

Palavras-chave: Tradição discursiva. Justaposição. Aquisição da escrita.

\section{INTRODUÇÃo}

"O objetivo deste trabalho, desenvolvido no âmbito do Grupo de Pesquisa Estudos sobre a Linguagem (GPEL/CNPq), é investigar, em dados de aquisição do modo escrito de enunciar, as construções predicativas conectadas de modo paratático por justaposição e, por meio dessa investigação, centrada em aspectos formais e semânticos das construções, examinar os fatores que contribuem para esse tipo de ligação, bem como para a emergência de um sentido no complexo. Para isso, procurarei mostrar, na linha de Pekarek-Doehler et al. (2010) e Thumm (2000), que propriedades morfossintáticas e semântico-lexicais se associam, intrinsecamente, a aspectos contextuais, em nivel discursivo, para a configuração dessa ligação.

Considero que, para a produção de enunciados, a criança lida com regras idiomáticas (sistema e norma) e regras discursivas, que pertencem ao domínio

* Universidade Estadual Paulista "Júlio de Mesquita Filho", São José do Rio Preto, SP, Brasil. E-mail: Iuciaregiane@bol.com.br 
das tradições discursivas (TDs). Segundo Kabatek (2005, 2006, 2008), as TDs englobam atos de fala, gêneros e tipos textuais, estilos, formas literárias etc., e referem-se aos modos tradicionais de dizer/escrever, reguladores da produção e recepção dos discursos ${ }^{1}$.

Para o reconhecimento de uma TD, as noções de evocação e repetição são fundamentais, isto é, textos já-ditos ou escritos são evocados pelo contexto de enunciação e repetidos total ou parcialmente. Dessa forma, a repetição está relacionada ao enunciado atual e aos textos evocados, presentes na memória dos sujeitos. Essa repetição pode ser apenas formal ou de uma combinação particular de elementos (KABATEK, 2005, 2006).

$\mathrm{O}$ autor relaciona a repetição, nesses termos, ao que chama de composicionalidade das TDs. De acordo com Longhin (2014), há duas perspectivas que podem ser exploradas a respeito da composicionalidade:

- A rede de tradições que um mesmo texto pode apresentar; por exemplo, como veremos no decorrer deste trabalho, num texto da TD contos de fadas podem mesclar-se as TDs narração, diálogo e descrição, entre outras.

- Os arranjos linguísticos, nas combinações sintagmáticas, dadas linearmente na língua, e nas escolhas paradigmáticas, que constituem uma finalidade de dizer, caracterizando, portanto, uma TD. Tais escolhas e combinações de elementos são direcionadas pelo conhecimento que o sujeito tem do que é fixo e lacunar numa tradição e, por conseguinte, também no sistema linguístico. Longhin (2014) cita, como exemplo, o caso de um texto pertencente à TD narrativa, em que é essencial a presença da relação temporal, em razão de sua finalidade comunicativa, enquanto característica fixa dessa tradição. No entanto, o modo como essa relação temporal é marcada, na materialidade linguística desse texto, é lacunar, ou seja, variável; se, por meio dos mecanismos de junção, poderá apresentar as arquiteturas sintáticas paratática ou hipotática, correlacionadas com especificidades semânticas, identificáveis nas diferentes formas de experimentação da relação temporal (simultaneidade, anterioridade, posterioridade, habitualidade), em ainda diferentes usos de mecanismos de junção (como quando, aí, logo que, enquanto, a própria justaposição, entre outros).

No âmbito das TDs, o ato comunicativo é filtrado pela organização linguística, na qual os signos são escolhidos seguindo as regras sintáticas e a norma de uma língua/variedade particular e, concomitantemente, pela ordem textual, responsável pela atualização de determinada $\mathrm{TD}^{2}$.

A noção de TD surgiu na Linguística Histórica Românica, no âmbito da Filologia Pragmática alemã, na década de 1980. O termo Diskurstradition, proposto por Koch (1997 apud LONGHIN, 2014) e adotado por outros linguistas alemães, como Oesterreicher e Kabatek, conceitua uma perspectiva histórica dos gêneros textuais (ASCHENBERG, 2002 apud ZAVAM, 2009) que, com base no entendimento teórico coseriano de "língua concreta", tem sido, mais recentemente, usada também em pesquisas que se debruçam sobre fenômenos textuais em um estado de língua sincrônico (cf. LONGHIN-THOMAZI, 2011a, 2011b; LOPES-DAMASIO, 2016; LOPES-DAMASIO, SILVA, 2017; SILVA, 2016, entre outros). O conceito de TD fundamenta-se, desse modo, em concepções teóricas de Coseriu, apoiadas na ideia de que a linguagem não é produto, mas atividade, recuperando, portanto, um diálogo com o pensamento aristotélico de Humboldt. Segundo Coseriu (1982), enquanto atividade criadora, a linguagem não possui caráter "acabado", de "coisa feita", "produto estático", mas de um conjunto de "modos de fazer", um sistema de produção que surge, apenas em partes, como produtos materializados linguisticamente, reconhecíveis como textos falados ou escritos.

2 Para exemplificar, a partir de uma situação de uso da língua, Kabatek (2005) retoma o fato de que, quando encontramos uma pessoa na rua pela manhã e a saudamos, não dizemos apenas "Saúdo você neste dia" ou "Dia bom para você", de acordo com as regras do primeiro filtro. Diferentemente, de acordo com as regras também do segundo filtro, usamos a expressão "Bom dia", uma construção discursiva constituída historicamente em nossa comunidade linguística. Nela, além das regras idiomáticas - como 
A abordagem da composicionalidade dessas tradições de dizer/escrever, no âmbito da junção, neste trabalho, especificamente da justaposição, pressupõe que a aquisição de TDs seja sempre processual (OESTERREICHER, 1997). Isso significa que, gradualmente, a criança apreende as propriedades fixadas e variáveis das TDs - o que apresentam como evocação do já-dito e o que apresentam como evocação de um projeto de dizer.

Assim, este trabalho concentra-se na seguinte questão: Com base em quê a relação entre os componentes de uma construção paratática justaposta se fundamenta? A hipótese é de que os componentes dessa construção devem ser analisados em seu contexto discursivo, em associação com suas propriedades morfossintáticas e semânticas. A análise desse contexto deve levar em consideração, por sua vez, a TD em que o enunciado se desenvolve.

A busca pela resposta à questão anterior, à luz da hipótese apresentada, justifica a opção por um modelo funcionalista de junção, fundado na não discretude dos processos e num arranjo bidimensional (RAIBLE, 2001), em que se entrecruzam o eixo tático e o das relações lógico-semânticas e cognitivas (KORTMANN, 1997), conjugado a uma base teórica que entende a escrita como constitutivamente heterogênea e como modo de enunciação (CORRÊA, 2004); e, ainda - inevitavelmente - a uma concepção de aquisição desse modo de enunciar que considera as tradições de falar/escrever (KABATEK, 2006).

Organizo este artigo em três partes, além desta, em que introduzo os seus objetivos sob o escopo teórico-metodológico das TDs. Na primeira, apresento a fundamentação teórica, destacando aspectos relativos ao tratamento dos dados, a partir de uma abordagem específica: 1. do nível sintático de análise, vislumbrado de forma não discreta; 2 . da aquisição da escrita, entendida fundamentalmente como processo; e 3 . do contexto, enquanto entorno textual e discursivo que privilegia as tradições de falar/escrever. A relação entre 1, 2 e 3 caracteriza uma abordagem que lança luz especialmente à conjugação desses vieses de análise, contemplando forma e sentido nas relações textuais-discursivas. Na segunda parte, apresento o material e o método de análise e, na terceira, uma proposta de análise contextualizada que, primeiro, projeta, sobre a interpretação das construções paratáticas justapostas, aspectos discursivos associados às características morfossintáticas e semânticas dos esquemas contrastivos destacados e, em seguida, propõe uma breve discussão à luz dos resultados dessa análise. Encerro com as considerações finais.

\section{QUADRO TEÓRICO: SINTAXE, AgUISIÇÃo DA ESCRITA E DISCURSO}

O termo parataxe inclui, a partir de uma abordagem funcionalista hallidayana (cf. HALLIDAY, 1985), estruturas que a gramática tradicional chama de justaposição assindética, ou seja, construções em que as orações têm o mesmo estatuto, sem qualquer elemento de ligação e que podem codificar quaisquer relações de sentido, desde as mais concretas, como a adição simétrica, até as mais abstratas, como a concessividade. Nessa direção, a identificação parataxe aponta para um traço do funcionamento tático, em oposição, por exemplo, à hipotaxe, enquanto a identificação justaposta aponta para um traço do mecanis-

aquela que prescreve, no português, a concordância do modificador adjetivo com o núcleo nominal -, há também as regras de uma tradição que mostra "como dizer" nesse contexto de enunciação - aquela tradição que, nesse caso, recomenda que o modificador esteja anteposto ao nome, diferentemente da maioria dos outros usos não tradicionais. 
mo por meio do qual essa taxe se efetiva, em oposição às construções, de mesma natureza, articuladas por outros mecanismos que não "zero" (Ø), como, por exemplo, e, ou, mas, por exemplo, isto é etc.

Segundo Thumm (2000, p. 4-5), a natureza exata da relação que se estabelece entre essas orações é determinada por meio de inferências discursivas, a partir do (co-)contexto em que ocorrem. Sendo assim, as construções paratáticas justapostas, muitas vezes tratadas como primitivas ou sintaticamente simples, não podem ser consideradas facilmente identificáveis e/ou definidas, uma vez que os contextos não são dados, não estão apenas lá como um conjunto pronto, preestabelecido, imutável, que os sujeitos simplesmente evocam. Eles são, ao contrário, dialogicamente estabelecidos e (re)ajustados durante a interação verbal. É necessário, pois, o reconhecimento de uma noção dinâmica de (con)texto, não dado como produto, mas como processo. É nessa perspectiva que assumo um entendimento próprio da face lacunar das TDs como projetos de dizer, que evocam, a partir de um diálogo com o já-dito, outros dizeres, novos e intrinsecamente associados ao seu locus de produção.

Nesse universo, os dados de aquisição da escrita caracterizam um material instigante para o estudo do processo pelo qual se constitui e modifica a complexa relação entre sujeito e linguagem, a partir de uma discussão acerca da natureza dinâmica dessa relação no âmbito de uma teoria da linguagem perpassada pelas TDs. Não se trata de observar a aquisição/aprendizagem da escrita unicamente enquanto sistema e norma de uma lingua, mas de observar a relação que se constitui entre sistema, norma e as tradições de falar/escrever, tomadas como filtro para a formulação dos enunciados.

Para construir o lugar teórico-metodológico dessa observação, recupero a afirmação de Abaurre, Fiad e Mayrink-Sabinson (2002, p. 22), de que

[...] a aquisição da escrita é um momento particular de um processo mais geral de aquisição da linguagem. Nesse momento, em contato com a representação escrita da língua que fala, o sujeito reconstrói a história de sua relação com a linguagem.

Desse ponto de vista, a posição de sujeito seria também, essencialmente, histórica, regulada pela linguagem - historicamente constituída - e pela atuação do outro, que o interpela, o afeta e é afetado por esse processo. O outro deve ser considerado em sua dimensão física e empírica, bem como enquanto instância de representação do funcionamento convencional da linguagem, na escrita, com base em representações que o sujeito faz sobre ele. Para Abaurre, Fiad e Mayrink-Sabinson (2002), o lugar desse processo é a interlocução entre sujeitos que se constituem em outros para seus interlocutores, constituindo-os também como sujeitos ${ }^{3}$.

De acordo com Corrêa (2008, p. 77-78), essas características indiciam a heterogeneidade da escrita e, consequentemente, estão fundamentadas no estatuto teórico que o autor atribui à fala/escrita e que é aqui adotado, em distanciamento, portanto: à noção de escrita como representação da língua, por meio da qual se opõem, de forma imprecisa e dicotômica, lingua falada e língua escrita; e, também à noção de fala e escrita como modalidades, já que, como são conhe-

\footnotetext{
No diálogo travado entre a criança e o adulto letrado, encontram-se indícios, segundo Abaurre, Fiad e Mayrink-Sabinson (2002) de que ambos se movimentam, já que o que o adulto faz e diz repercute no que a criança faz e diz e vice-versa. $\mathrm{O}$ adulto letrado constitui-se num outro, que confronta o sujeito-criança com a ideia de que a escrita veicula sentidos e não é simples sequência de letras desenhadas ao acaso, o que desencadeia, nesse sujeito, a busca por esses sentidos. A criança, também se constituindo num outro para o sujeito-adulto letrado, confronta-o com sua leitura, "sem sentido" para ele, que busca, com sua visão de letrado, na escrita, exigências que só fazem sentido para quem já lê e já escreve. Ao não utilizar as convenções preestabelecidas pelo sistema, a criança força o adulto a rever sua leitura e a aceitar o que é oferecido por ela como um sentido (dentre outros).
} 
cidas e utilizadas, as modalidades oral e escrita definem-se a partir de referências às suas bases semióticas: o som (fala) e o traço gráfico (escrita), sendo que essa diferença tem servido como base inapropriada para a validação da oposição radical entre práticas faladas e escritas, como se, nelas, o aspecto semiótico fosse o único relevante ${ }^{4}$.

No lugar dessas noções, assumo, com Corrêa (2004), a proposta de fala e escrita como modos de enunciação, em que a escrita, apesar de se mostrar como enunciação solitária, nunca se realiza sem a presunção de um leitor, o que a aproxima do modo de enunciação da fala, em que, mais do que a presença física dos interlocutores, conta sua representação (CORRÊA, 2008, p. 78). Portanto, o modo escrito de enunciação é visto, neste trabalho, como espaço que privilegia a observação de manifestações da singularidade dos sujeitos, tomadas aqui como hipóteses e operações desses sujeitos, e não como faltas/erros.

As hipóteses e operações dos sujeitos, na aquisição da escrita, associam-se não apenas à alfabetização, como é tradicionalmente entendida, mas também à observação das diferentes TDs, abrangendo as regras da lingua, as regras das TDs e a forma como o sujeito se relaciona com elas, ou seja, abrangendo uma concepção de letramento - subjacente a um processo amplo de natureza sociohistórica, relacionado às práticas de leitura e de escrita -, para a qual importa a inserção do sujeito em práticas discursivas que constituem modos variados e complexos de representação dos significados de ler e escrever, em diferentes contextos sociais (STREET, 2006). A inserção do sujeito que "aprende a escrever" em práticas formais de letramento envolve, pois, além do próprio processo de codificação e decodificação, pressuposto na alfabetização, uma relação dialógica entre essas práticas e aquelas típicas da oralidade.

Como os autores citados, não estou propondo, com essa postura teórica, um caminho natural e direto do oral para o escrito, mas destacando o papel das tradições da oralidade, que a criança já domina, em sua aquisição do modo escrito de enunciar. Ao papel da oralidade, soma-se, ainda, o papel das tradições que estarão ligadas à imagem da escrita veiculada pela escola. As tradições orais e formais e essa imagem de escrita ligam-se à presença do outro, interlocutor fisicamente presente ou representado e ponto de referência necessário para o sujeito e sua escrita em constituição.

\section{MATERIAL E MÉtodo DE INVESTIGAÇÃo}

O universo da investigação é composto por 100 textos extraídos do banco de dados sobre aquisição da escrita infantil, pertencente ao GPEL. Para a constituição desse banco, as propostas foram elaboradoras e aplicadas, com periodicidade quinzenal, e os alunos, acompanhados de 2001 a 2004, durante as quatro primeiras séries do ensino fundamental, sempre em contexto escolar. Os textos extraídos desse banco, para as análises apresentadas neste artigo, são produções de alunos, especificamente, das antigas primeira e segunda séries (2001-2002) da

4 A concepção de escrita constitutivamente heterogênea, assumida aqui, afasta-se radicalmente, portanto, daquelas fundamentadas numa dicotomia entre fala e escrita e distancia-se, ainda, daquela proposta por Koch e Oesterreicher (2007), seguidos no Brasil por Marcuschi (1997, 2001), conhecida como dicotomização metodológica da relação fala/escrita. Nessa proposta, há a criação de um contínuo tipológico de gêneros textuais, no qual se localizam os referidos pontos intermediários entre os extremos do suposto como típico oral, de um lado, e do suposto como típico escrito, de outro. Nela, as bases semióticas assumem papel de relevância para a constituição do contínuo de textos, embora atreladas a outros fatores, vinculados a saberes sociais. Para os autores, tratase de noções solidárias que devem ser avaliadas a partir do meio de realização (fônico ou gráfico) e da concepção de texto oral e texto escrito, que pode se dar num "contínuo de intermináveis formas intermediárias" (KABATEK, 2002, p. 42). 
escola pública Romano Calil, localizada na periferia da cidade de São José do Rio Preto, São Paulo.

Quanto ao método de análise, são conjugadas as abordagens quantitativa e qualitativa, em duas etapas principais: 1. análise das paratáticas justapostas a partir da consideração de aspectos contextuais-discursivos determinantes para a caracterização das construções; 2 . conjugação dessa análise com aspectos das TDs.

Para a apresentação dos resultados, exponho, neste trabalho, os dados quantitativos relativos a 1, com a frequência token de ocorrência da justaposição, nos textos analisados, em todas as suas manifestações lógico-semânticas; bem como apresento os dados qualitativos referentes a 2 , fruto da conjugação da análise das paratáticas justapostas à consideração de seus aspectos contextuais-discursivos, em diferentes TDs. Para isso, apresento, a título de exemplificação, as análises de três textos produzidos a partir das propostas 4, 10 e 11, conforme Quadro 1. Nessas análises, focalizo, especificamente, o padrão semântico de contraste em consonância com os aspectos contextuais-discursivos inerentes à sua construção.

Quadro 1 - Propostas de produção textual

\begin{tabular}{|l|c|l|}
\hline \multicolumn{1}{|c|}{ Propostas } & Textos & \multicolumn{1}{c|}{ Descrição da proposta } \\
\hline $\begin{array}{l}\text { P(10) } \\
\text { Sobre o } \\
\text { quadro }\end{array}$ & (1) & $\begin{array}{l}\text { O pesquisador apresentou algumas cópias do trabalho de } \\
\text { Lasar Segall - as pinturas: Retrato de Lucy, Paisagem } \\
\text { brasileira, Floresta crepuscular, Interior de pobres II, O } \\
\text { encontro - e uma foto do autor com cerca de 29 anos de } \\
\text { idade. Depois, pediu às crianças que imaginassem que } \\
\text { seriam artistas (pintores) e deveriam fazer um esboço de } \\
\text { um quadro e descrevê-lo (nome, tipo de material e porque } \\
\text { elas haviam feito ou fariam tal quadro). }\end{array}$ \\
\hline $\begin{array}{l}\text { P(4) } \\
\text { Carta à } \\
\text { presidência }\end{array}$ & (2) & $\begin{array}{l}\text { O pesquisador perguntou às crianças se elas sabiam quem } \\
\text { seriam os candidatos à presidência. Tendo obtido respostas } \\
\text { afirmativas, listou, com elas, na lousa, cinco candidatos e } \\
\text { solicitou que escrevessem uma carta a um deles, falando- } \\
\text { lhe sobre o que elas achavam que ele deveria fazer para } \\
\text { melhorar o Brasil. }\end{array}$ \\
\hline $\begin{array}{l}\text { P(11) } \\
\text { Convite } \\
\text { para Érica }\end{array}$ & (3) & $\begin{array}{l}\text { O pesquisador disse às crianças que elas iriam produzir } \\
\text { um convite para a jornalista Érica, que viria visitá-los para } \\
\text { falar sobre como era o trabalho no jornal e como podem ser } \\
\text { escritas matérias de jornal. Combinou com as crianças que } \\
\text { apenas os dois melhores convites seriam entregues à } \\
\text { jornalista em nome de toda classe - um representando as } \\
\text { meninas e, outro, os meninos. }\end{array}$ \\
\hline
\end{tabular}

Nos textos produzidos a partir das propostas apresentadas no Quadro 1, foram constatadas mais de uma $\mathrm{TD}$, tal como sintetizo a seguir:

- $\mathrm{P}(4)$ Carta à presidência - a necessidade de produzir a TD carta direciona a outras TDs que tomam lugar, especialmente, no miolo da carta. Como nessa proposta o escrevente precisa falar sobre o que ele acha que os candidatos deveriam fazer, a TD argumentativa também se efetiva, já que 
surge a necessidade de justificar esse achar. Na mesma linha, a possibilidade de inserção de instruções/ordens/conselhos a esses candidatos abre espaço para a TD injuntiva.

- $\mathrm{P}(10)$ Sobre o quadro - o escrevente realiza a TD descrição, em enunciados centrados na descrição de seu desenho e, também, a TD argumentação, na explicitação da escolha por determinado desenho.

- $\mathrm{P}(11)$ Convite para Érica - a confecção de uma TD convite para o escrevente significa também a necessidade de argumentar, para que esse convite seja aceito ${ }^{5}$.

$\mathrm{Na}$ sequência, apresento uma proposta de análise, caracterizada, centralmente, pela projeção, sobre a interpretação das construções paratáticas justapostas com acepção contrastiva, de aspectos discursivos que se associam às características morfossintáticas e semânticas dos esquemas destacados. Para isso, a proposta também se caracteriza pela conjugação dessa análise com a abordagem da TD, de modo a correlacionar os resultados da descrição analitica - morfossintática e semântica - com o que é previsto para os modos de dizer/ escrever focalizados.

\section{DA MORFossintaXe AO SENTIDo DE CONTRASTE EM TRAdiçÕES DISCURSIVAS}

Em dados de aquisição da escrita, os sujeitos optam preferencialmente por esquemas de junção com e e justaposição na codificação de várias relações de sentido, mais ou menos concretas, conforme já mostraram estudos anteriores, por exemplo, de Lopes-Damasio (2016), Tuão-Brito (2014) e Longhin-Thomazi (2011a, 2011b), e conforme mostra o Gráfico 1:

Gráfico 1 - Frequência token dos mecanismos de junção

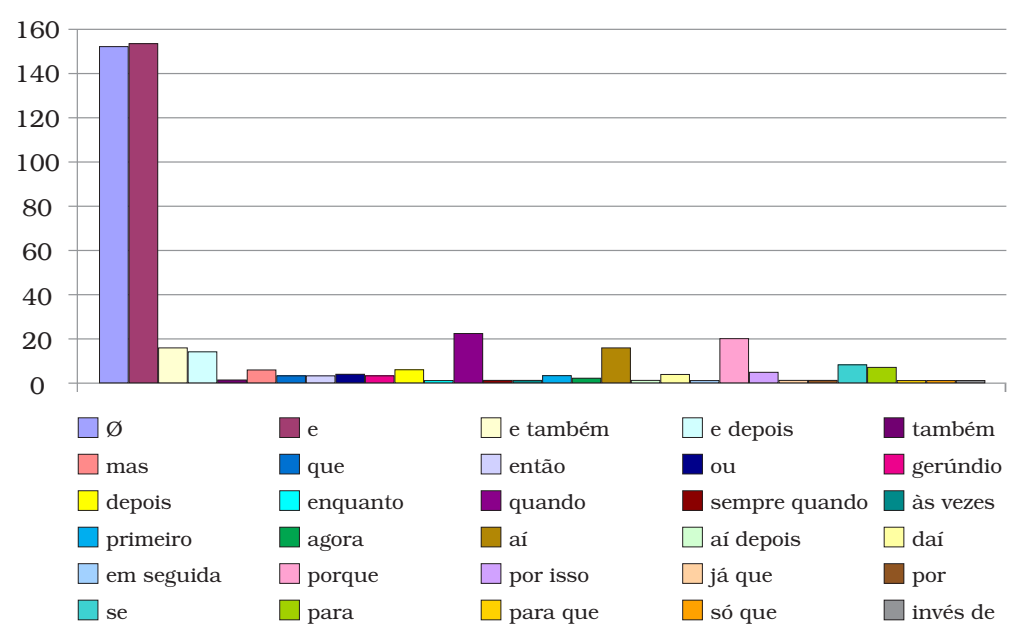

Fonte: Tuão-Brito (2014).

5 Fica evidente, nesta explicação metodológica, que o conceito de TD abarca, portanto, os gêneros discursivos/textuais, como a carta e o convite, bem como os tipos textuais, como a argumentação, a descrição e a injunção, de acordo com seu princípio de composicionalidade. Para além dessas correlações, o conceito pode corresponder, ainda, a construções textuais que tomam lugar no interior desses espaços textuais-discursivos, constituindo-os, como, por exemplo, Era uma vez..., recorrente nos contos de fadas. 
Resultados dessa natureza justificam o escopo eleito para este trabalho, que focaliza especificamente a justaposição oracional, enquanto mecanismo de junção comprovadamente produtivo na aquisição e no desenvolvimento do modo escrito de enunciar. Nessa direção, a Tabela 1 apresenta resultados quantitativos, alcançados a partir do material analisado para este trabalho - textos da primeira e segunda séries do ensino fundamental (CALIL 1 e CALIL 2), com a exposição da frequência token da justaposição, conjugada à frequência dos diferentes tipos de relações de sentido e elencada em uma escala de complexidade cognitiva crescente:

Tabela 1 - Frequência da justaposição em dados de aquisição da escrita

\begin{tabular}{|c|c|c|c|c|c|c|c|}
\hline$\varnothing$ & Adição & Modo & $\begin{array}{c}\text { Tempo } \\
\text { simul. }\end{array}$ & $\begin{array}{c}\text { Tempo } \\
\text { post. }\end{array}$ & Causa & Contraste & Total \\
\hline CALIL 1 & $\begin{array}{c}81 \\
26,21 \%\end{array}$ & 0 & 0 & 45 & 17 & 1 & 144 \\
\hline CALIL 2 & 81 & 1 & 1 & 53 & 25 & 4 & 165 \\
& $26,21 \%$ & $0,32 \%$ & $0,32 \%$ & $17,15 \%$ & $8,09 \%$ & $1,29 \%$ & $53,39 \%$ \\
\hline \multirow{2}{*}{ Total } & 162 & 1 & 1 & 98 & 42 & 5 & $50,56 \%$ \\
& $52,42 \%$ & $0,32 \%$ & $0,32 \%$ & $31,71 \%$ & $13,59 \%$ & $1,61 \%$ & $100 \%$ \\
\hline
\end{tabular}

De acordo com a Tabela 1, os textos da primeira e segunda séries não apresentam ocorrências que configurem comportamentos muito divergentes no que diz respeito à produtividade da justaposição em cada uma das relações de sentido constatadas (adição, modo, tempo - simultâneo e posterior -, causa e contraste). Ou seja, a justaposição é frequentemente usada para a codificação da noção de adição nos textos analisados de ambos os anos, representando um total de $52,42 \%$ das noções de sentido constatadas no material. Em seguida, esse mecanismo de junção encontra maior produtividade na noção de tempo posterior, com $31,71 \%$ das ocorrências, seguida pela causalidade, com 13,59\%. Chama atenção a redução gradativa da frequência de uso dessas noções à medida que vão se abstratizando ou tornando-se mais complexas do ponto de vista semântico-cognitivo (adição > tempo posterior > causa). Além disso, destaca-se também o fato de que, apesar de sua frequência reduzida, a noção de contraste caracteriza a acepção mais abstrata experimentada pelos escreventes em aquisição do modo escrito de enunciar, no corpus analisado. Diante disso, vale investigar o modo como a relação entre os componentes de construções paratáticas justapostas contrastivas se fundamenta.

Para essa investigação, parto da verificação empírica que comprova a ampliação da frequência dos usos da justaposição nos textos da segunda série (CALIL 2), como mostro no Gráfico 2, o que contrasta com as teses que atribuem simplicidade à parataxe, especialmente à justaposição, e associam-na à sintaxe da língua falada (em uma visão dicotômica) e das línguas em seus estágios mais primitivos. 
Gráfico 2 - Justaposição em dados da $1^{\mathrm{a}}$ e $2^{\mathrm{a}}$ séries do ensino fundamental

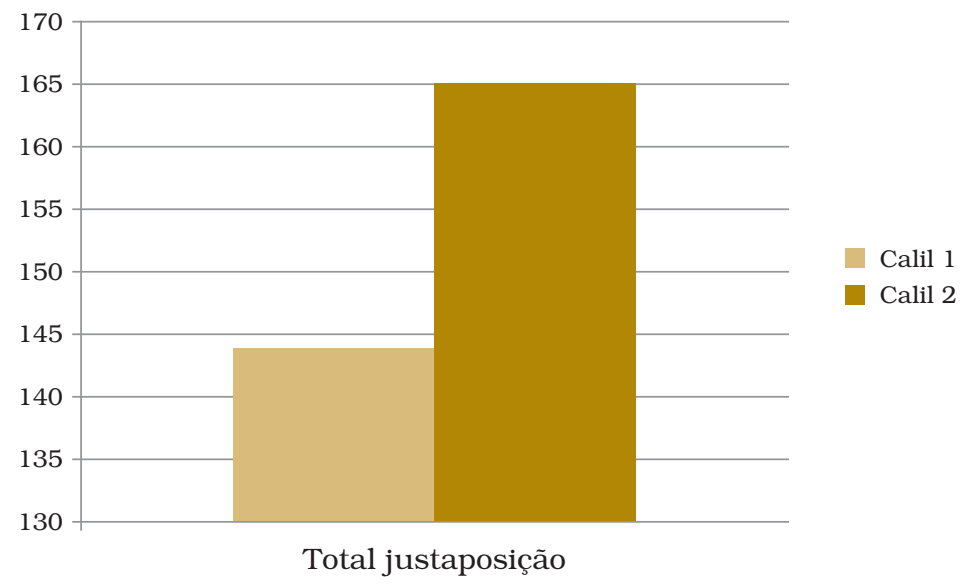

A análise revela que, em vez dessa simplicidade e/ou primitivismo sintático, em textos menos desenvolvidos, na $1^{\mathrm{a}}$ série, e mais desenvolvidos, na $2^{\mathrm{a}}$, diferentes relações semânticas são codificadas, via mobilização dialógica de contextos, intrinsecamente associadas às TDs. Essa ampliação é explicada pelo uso dessa estratégia de junção, a justaposição, na codificação de uma gama maior de relações de sentido (uma vez que, em CALIL 1, são constatadas quatro relações de sentido, enquanto, em CALIL 2, são constatadas seis). O Gráfico 3 retoma e ratifica os dados apresentados na Tabela 1:

Gráfico 3 - Relações de sentido da justaposição em dados de $1^{\mathrm{a}}$ e $2^{\mathrm{a}}$ séries do ensino fundamental

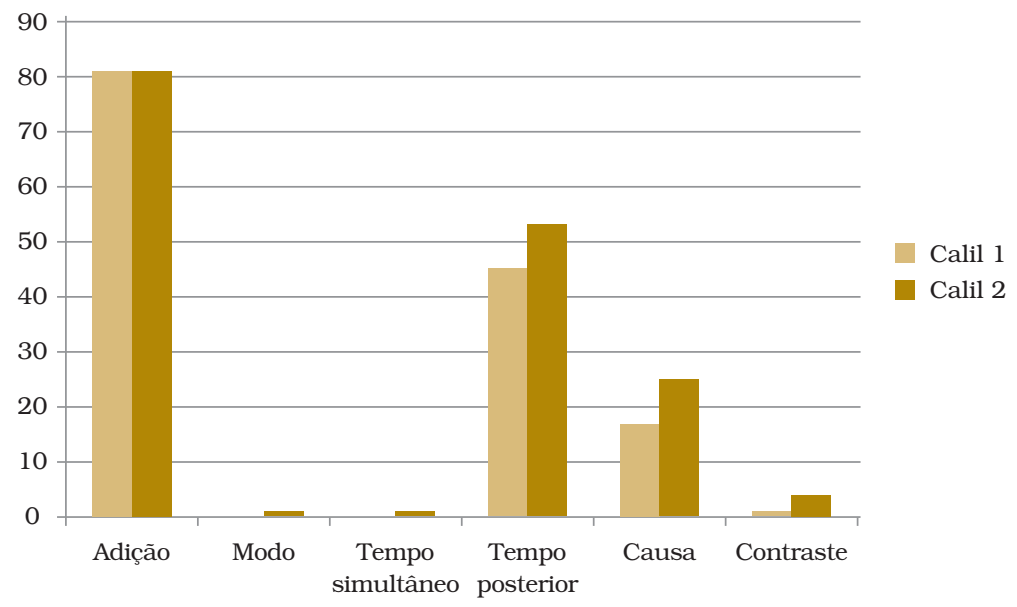

Dessa forma, embora não seja muito recorrente nos textos investigados, a configuração da relação de contraste, entendida aqui nos moldes de Pekarek-Doehler et al. (2010, p. 4), não como uma operação lógica, ou simplesmente 
uma relação semântica entre duas construções predicativas conectadas de forma paratática, mas como uma atividade realizada pelo sujeito, em que as estruturas, ainda que não marcadas morfossintaticamente, são usadas com a função de atuar como recurso para um fim pretendido, assume nuanças semântico-discursivas interessantes para ilustrar a relação, investigada neste trabalho, entre forma (justaposição paratática), sentido (contraste) e tradição de escrever (em enunciados relativamente estáveis que se mesclam quanto aos modos escrito e falado de enunciar). Essa relação pode ser apoiada por uma série de outros meios sintáticos, léxico-semânticos e prosódicos, que auxiliam na criação de paralelos para estabelecer diferenças e/ou refutações que conferem aos enunciados funções argumentativas com base no conhecimento de mundo e nas expectativas do falante/escrevente.

Algumas dessas funções são alimentadas, de forma mais pontual, por correlatos linguísticos, como os que destaco nos textos (1) e (2), outras se constituem de forma mais global, em dependência discursivo-contextual, como destaco no texto (3):

Figura 1 - Sobre o quadro [Calil 2-P(10)]. Texto (1)

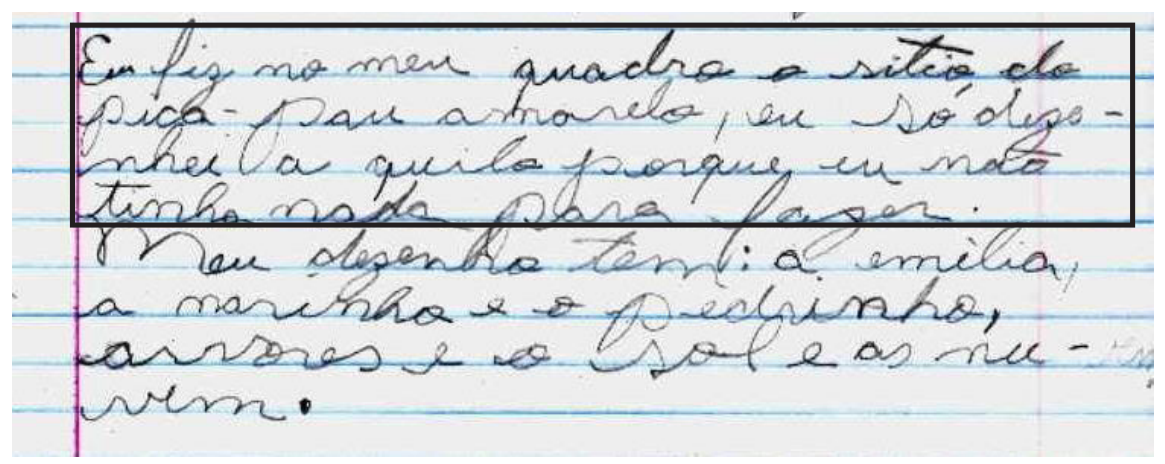

Para a análise de (1), importa retomar a $\mathrm{P}(10)$, que propôs ao sujeito que se imaginasse artista (pintor) e esboçasse um quadro, para que, em seguida, pudesse descrevê-lo, abrindo espaço, dessa forma, para a produção de textos tradicionalmente descritivos e composicionalmente constituídos também por meio da argumentação.

Diante dessa proposta de esboçar um quadro e depois descrevê-lo, o sujeito, não se sentindo inspirado, cumpre a atividade, mas torna recuperável o contraste presente no momento em que argumenta em relação à sua escolha, tal como fica claro no trecho destacado: em (1), a sequência binária de ordem rígida - "Eu fiz no meu quadro o sítio do pica-pau amarelo, $\varnothing$ eu só desenhei aquilo porque eu não tinha nada para fazer" - mostra uma manobra argumentativa para a marcação de contraste decorrente do uso de só, associado à negação explícita não tinha nada para fazer, que integra a causal que compõe, por sua vez, o segundo membro paratático.

Neste enunciado, o sujeito simula uma interlocução entre duas figuras, a própria criança, que representa a si mesma, e outra em que representa o outro/ destinatário que, ao mesmo tempo, coincide com um participante-interlocutor direto do diálogo e o professor/pesquisador. Diante dessa representação e do 
que lhe foi proposto, no contexto formal da escola, a criança escrevente cumpre sua tarefa, pontuando-a com a marcação de contraste.

A negativa explícita aliada ao paralelismo sintático para marcação de contraste pode ser observada também no enunciado em (2), produzido com base na $\mathrm{P}(4)$ Carta à presidência, em que o sujeito, nas tradições injuntiva e argumentativa, estabelece um diálogo direto com o seu outro/destinatário, José Serra.

Figura 2 - Carta à presidência [Calil 2-P(4)]. Texto (2)

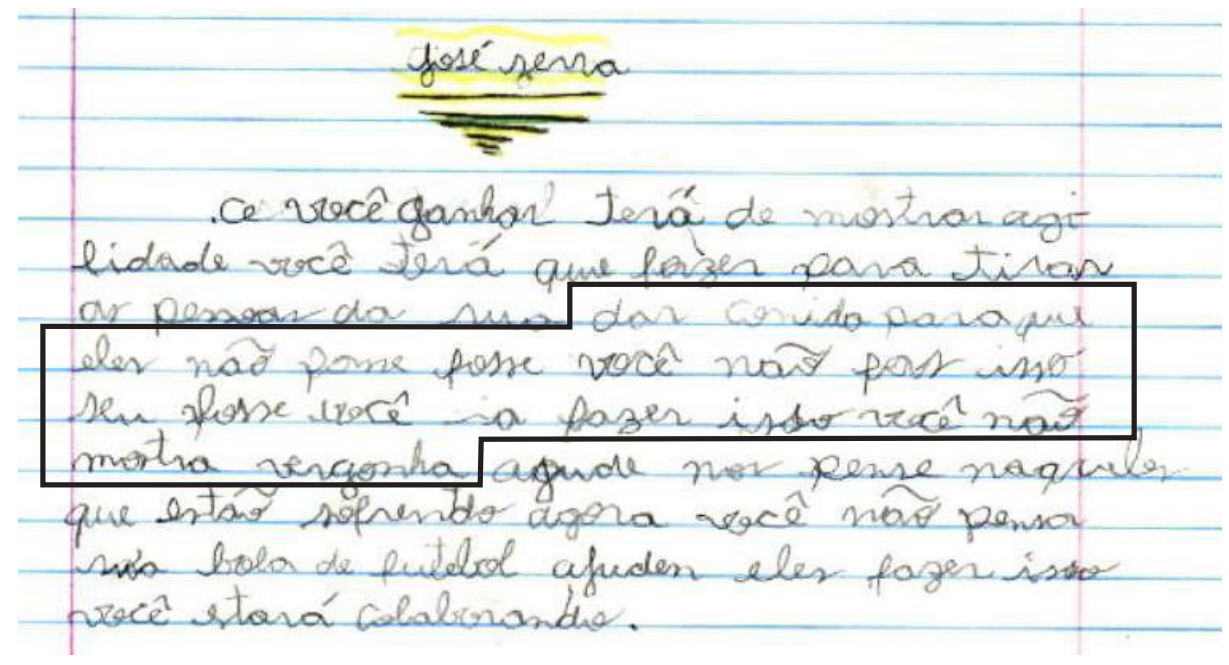

Nesse enunciado fortemente dialógico ${ }^{6}$, há duas sequências paratáticas justapostas nos pares, que se seguem: 1. "dar comida para que eles não passem fome $\varnothing$ você não faz isso" e 2 . "se eu fosse você ia fazer isso $\varnothing$ você não mostra vergonha”. Em 1, o contraste é estabelecido pelo sujeito entre o que o candidato deveria fazer, mas não faz, na avaliação deste sujeito, representado como eu que se dirige ao outro, identificado. Em 2 - inserida imediatamente, de forma recursiva -, o primeiro par, composto por uma condicional, coloca em contraste esse eu, que se hipotetiza no lugar do outro, e o outro (você) apresentado na segunda oração do complexo. Nesse par, estão subjacentes, numa integração discursiva, duas posturas distintas: "você não faz isso, porque você não tem vergonha e isso o faz diferente de mim, que faria isso [e que, portanto, tenho vergonha]". As negativas (fazer $\mathrm{x}$ não fazer), acrescidas a posições pessoais avaliadas e qualificadas de formas distintas pelo sujeito (a do eu $\mathrm{x}$ a de você) marcam diferenças de perspectivas, a partir da perspectiva do sujeito, que, legitimadas por princípios do mundo real - nesse caso, ligados a um conjunto de posturas esperadas por parte de políticos -, dão margem à leitura de contraste.

Também no texto que segue, o contraste é marcado por uma oposição entre eu e você. Apesar disso, o direcionamento discursivo, em (3), é distinto daquele visto em (2): 
Figura 3 - Convite para Érica [Calil 2-P(11)]. Texto (3)

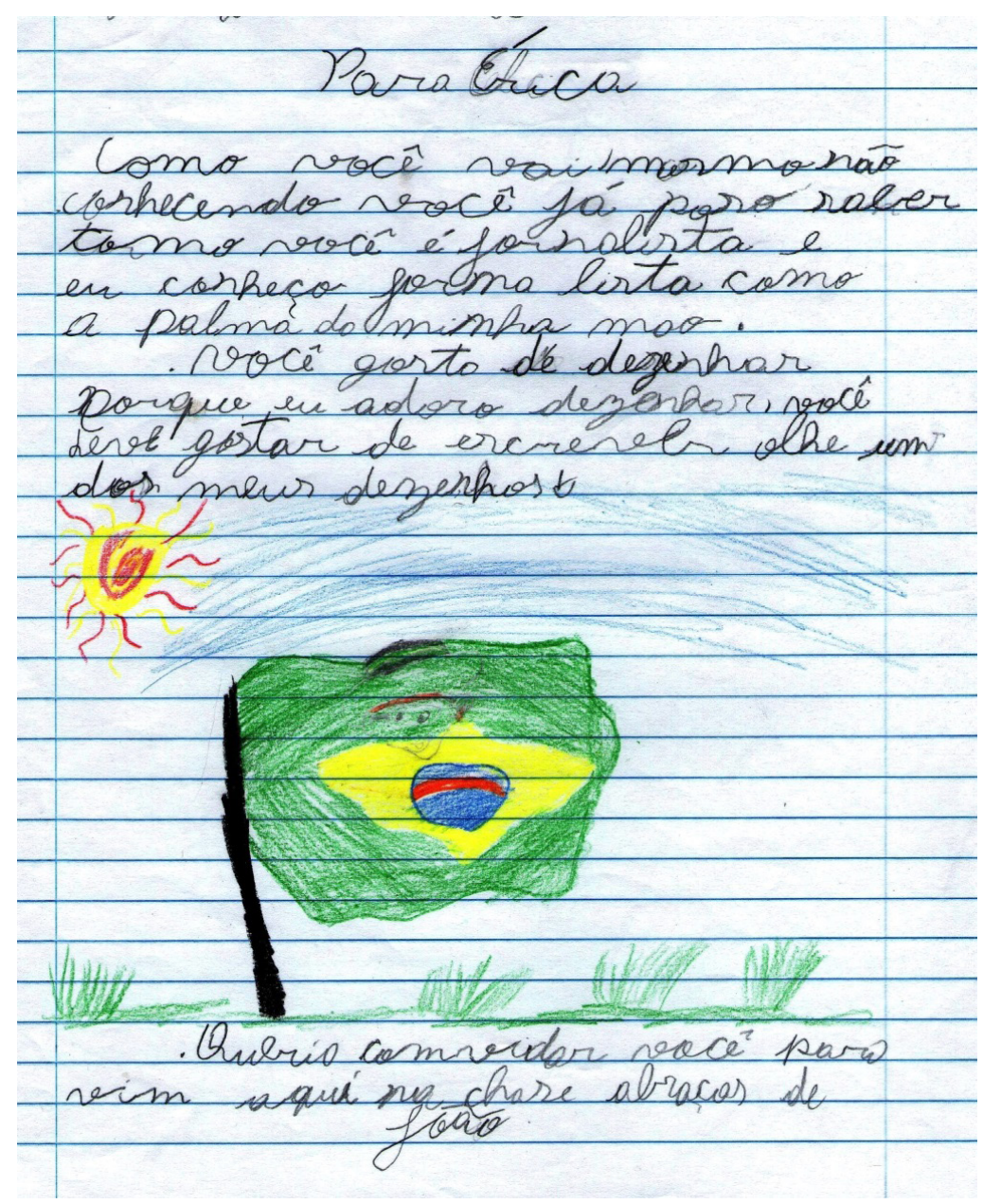

No enunciado em (3), produzido a partir da $\mathrm{P}(11)$ Convite para Érica, estão presentes traços tradicionais de convites escritos, como o endereçamento "Para Érica" e o propósito explícito do ato: "Queria convidar você para vim aqui na classe”. Há, entretanto, aspectos que ligam esse enunciado à tradição de convidar pessoas oralmente, que remetem a um diálogo, muitas vezes informal, e que se inicia com uma tentativa de aproximação do interlocutor, verificada em "Como você vai?" e que se estende pelo desenvolvimento do texto, em que o sujeito investe nessa aproximação, mesmo em um contexto que a desfavoreça.

Assim, a relação contrastiva está presente em todo o desenvolvimento de (3), sendo codificada de formas diferentes. No início, o sujeito afirma: "mesmo não conhecendo você, já posso saber como você é: jornalista". Ou seja, representando seu outro/destinatário participante-interlocutor, a partir de seu conhecimento de mundo sobre o que é e como é um jornalista - o que afirma conhecer "como a palma de sua mão" -, o sujeito, embora não conheça a "pessoa" jornalista, consegue estabelecer expectativas em relação a ela e projetar seu propósito 
discursivo de tentar aproximar-se desse outro/destinatário, diferentemente do que se observou no texto anterior.

Outro indício dessa tentativa de aproximação materializa-se na pergunta "Você gosta de desenhar?". A inserção desse ato de perguntar é justificada pela paratática causal "porque eu adoro desenhar" (o que, por sua vez, é evidenciado pela apresentação de um desenho no texto). No entanto, recursivamente, essa oração passa a funcionar no par justaposto "porque eu adoro desenhar $\varnothing$ você deve gostar de escrever", que, em seu binarismo ordenado, estabelece novamente um contraste, marcado no léxico (desenhar versus escrever), mas, principalmente, no discurso. Ora, se o sujeito conhece os jornalistas como a palma de sua mão, é de se esperar que seja de seu conhecimento que jornalistas gostam de escrever. Esse contraste não obscurece, contudo, o desejo de aproximação do outro, marcado e reforçado, por esse sujeito. Toda essa estratégia discursiva que explicita uma tentativa de aproximação entre o eu e o outro/destinatário, mesmo em um contexto marcado por contrastes, justifica-se no intuito de enunciar um convite a esse outro/destinatário e tê-lo aceito. Vale lembrar que, de acordo com o que foi explicitado nessa proposta, apenas os dois melhores convites da classe seriam, de fato, entregues ao destinatário. Fica evidente que, para o sujeito que escreve esse convite, os melhores convites seriam aqueles que tivessem maiores chances de serem aceitos.

\section{Discussão dos RESUltados}

Neste trabalho, a análise das construções justapostas, em dados de aquisição do modo escrito de enunciar, permitiu confirmar a hipótese de que a ligação entre os membros dessa construção e a relação de sentido que emerge dela são discursivamente decorrentes. Sendo assim, foi possivel mostrar que, para a compreensão adequada desse tipo de construção, a consideração de questões inerentes às TDs é tão relevante quanto a de suas propriedades morfossintáticas, semântico-lexicais e prosódicas. Isso porque, no ambiente discursivo de uma dada TD, frames/esquemas/scripts são evidenciados e, para que as expectativas deles decorrentes sejam atendidas, algumas relações de sentido, ainda que não estejam explicitamente marcadas, são mais esperadas que outras. Nessa direção, o contraste, conforme ilustrado, excede o domínio lógico-semântico e efetiva-se à luz de relações discursivas, intrínsecas ao conhecimento de mundo e ao conjunto de crenças dos participantes da interação, especialmente do sujeito-escrevente, em determinados enunciados, em que se verifica o traço recorrente da argumentação $o^{7}$.

Seguindo os resultados apresentados por Capristano e Oliveira (2014), mostrou-se relevante, neste trabalho, a representação que o escrevente faz do outro/destinatário de seu enunciado, que emerge, nos textos, concomitantemente voltada para: 1. o outro instituição escolar que não pode deixar de ser reconhecido, visto que todos os textos pertencem a uma macro TD escolar, enquanto tradição de escrever que se configura exclusivamente no contexto formal da escola; 2. o outro professor/pesquisador; e 3. o outro participante-interlocutor direto do diálogo.

7 Com isso, efetua-se uma ligação entre a justaposição com acepção contrastiva e a TD argumentativa. 
É importante, da mesma forma, associar a essa questão a dependência dos enunciados ao contexto de enunciação, em que o sujeito que escreve e o sujeito que lê compartilham a mesma situação de enunciação. É esse aspecto que permite ao primeiro apontar para ela (a situação) na configuração dos sentidos do texto. Nesse universo, o uso das justaposições é um gesto da criança/escrevente que indicia o fato de que ela conta com esse conhecimento partilhado com seu outro/destinatário/leitor, no momento da enunciação. Sendo assim, na mesma linha de Capristano e Oliveira (2014, p. 355) e Corrêa (2004), sugiro que, por acreditar que o contexto em que o seu enunciado foi produzido está plasmado em sua escrita, a criança junta as orações de forma justaposta, sem explicitar, por mecanismos táticos de junção, a codificação das mais diferentes relações de sentido - tal como a de contraste aqui focalizada -, da mesma forma como realiza outras manobras, como a utilização de expressões nominais definidas e pronomes sem referentes, investigadas em outros trabalhos (cf. CAPRISTANO; OLIVEIRA, 2014).

É ainda importante lembrar que esse gesto do sujeito, em fase de aquisição do modo escrito de enunciar, apresenta uma especificidade, enquanto gesto que se realiza em enunciados relativamente estáveis; ao mesmo tempo que aponta para o contexto, deixa pistas também no co-texto, ou seja, marcas linguísticas que aproximam o outro/destinatário da relação de sentido pretendida. Isso indica que o sujeito se insere na escrita, circulando pelo fixo, mas também pelo lacunar das tradições.

\section{CONSIDERAÇÕES FINAIS}

A partir do objetivo de investigar, em dados de aquisição do modo escrito de enunciar, as paratáticas justapostas por meio de uma abordagem centrada nos aspectos morfossintáticos e semânticos dessas construções, mas também naqueles de natureza discursiva, o exame dos fatores que contribuem para esse tipo de ligação oracional levou em consideração a TD em que o enunciado se desenvolve e mostrou a natureza da emergência do sentido contrastivo nesses complexos.

Sintetizando, aponto três considerações importantes que resultam desse estudo:

1. Quanto à composicionalidade da TD: na composição sintagmática de determinada tradição atuam outras tradições de forma dinâmica (o que estou chamando de mescla de TDs). O fator que rege esse princípio de composicionalidade das TDs é fortemente discursivo, no sentido de que são os propósitos discursivos do sujeito, segundo suas representações de dado momento, espaço de interlocução e outro/destinatário de seu enunciado, que determinam quais tradições atuam como matéria para a produção de uma tradição.

2. Quanto à natureza da justaposição: a justaposição revela-se como um mecanismo de junção produtivo nos dados de aquisição do modo escrito de enunciar e pode ser discursivamente descrita como um gesto do escrevente, que aponta, no espaço gráfico, para a situação concreta de sua enunciação, uma vez que o sujeito imprime, na construção de tradições 
da escrita, suas experiências com as tradições da oralidade, especialmente o diálogo.

3. Quanto à relação entre TD e justaposição contrastiva: a relação de contraste, codificada em justaposições oracionais, conforme ilustrado, efetiva-se no interior da TD argumentativa, constitutiva dos textos analisados, no âmbito de mesclas de TDs e em consonância com o propósito de seus escreventes de atender ao que lhes fora solicitado na proposta de produção textual. Essa relação contrastiva efetiva-se para além do domínio lógico-semântico, de forma intrinsecamente associada a relações discursivas, que, por sua vez, caracterizam a tradição de argumentar e se efetivam em correlação ao conhecimento de mundo e ao conjunto de crenças do escrevente, tendo em vista o outro e as condições em que produz o seu texto.

\section{The ClaUSAL JUXTAPOSITION IN WRITING ACgUISITION}

Abstract: On this paper, we take on a functional model of junction (RAIBLE, 2001), an understanding related to the writing as constitutively heterogeneous and as a form of enunciation (CORREA, 2004) and a conception of acquisition of writing that considers discursive traditions (KABATEK, 2006), aiming at a linguistic discursive thought on juxtaposed paratactic constructions, regarding writing acquisition. The results indicate that, according to the investigated data, the mixture of discursive traditions and the junctions that occur in the same tradition are recurrently engaged by juxtaposition, while gesture that points at the concrete enunciation situation in the graphical space.

Keywords: Discursive tradition. Juxtaposition. Writing acquisition.

\section{REFERÊNCIAS}

ABAURRE, M. B. M.; FIAD, R. S.; MAYRINK-SABINSON, M. L. T. Cenas de aquisição de escrita: o sujeito e o trabalho com o texto. São Paulo: Mercado de Letras, 2002.

CAPRISTANO, C. C.; OLIVEIRA, E. L. Escrita infantil: a circulação da criança por representação sobre gêneros discursivos. Alfa, São Paulo, v. 58, n. 2, p. 347-370, 2014.

CORRÊA, M. L. G. O modo heterogêneo de constituição da escrita. São Paulo: Martins Fontes, 2004.

CORREAA, M. L. G. Arranjos referenciais de tempo em textos de pré-universitários: letramento e oralidade. Gragoatá, Rio de Janeiro, n. 25, p. 75-93, jul./dez. 2008.

COSERIU, E. O homem e sua linguagem. Rio de Janeiro: Presença, 1982.

HALLIDAY, M. A. K. Above the clause: the clause complex. In: HALLIDAY, M. A. K. An introduction to functional grammar. New York: Arnold, 1985.

KABATEK, J. Oralidad, proceso y estructura. Pandora, n. 2, p. 37-54, 2002.

KABATEK, J. Tradiciones discursivas y cambio lingüistico. Lexis XXIX, v. 2, p. 151-177, 2005. 
KABATEK, J. Sobre a historicidade dos textos. Linha d'água, n. 17, p. 157-170, 2006.

KABATEK, J. Introduccion. In: KABATEK, J. (ed.). Sintaxis histórica del español y cambio lingüistico: nuevas perspectivas desde las tradiciones discursivas. Madrid: Iberoamericana, 2008.

KOCH, P.; OESTERREICHER, W. Lingua hablada en la romania: Espanol, Francés, Italiano. Madrid: Editorial Gredos, 2007.

KORTMANN, B. Adverbial subordination: a typology and history of adverbial subordinators based on European languages. Berlin; New York: Mouton de Gruyter, 1997.

LONGHIN, S. R. Tradições discursivas: conceito, história e aquisição. São Paulo: Cortez, 2014.

LONGHIN-THOMAZI, S. R. Aquisição de tradições discursivas: marcas de uma escrita heterogeneamente constituída. Alfa, São Paulo, v. 55, n. 1, p. 225-248, 2011a.

LONGHIN-THOMAZI, S. R. Junção e(m) aquisição: aspectos morfossintáticos e cognitivos. Gragoatá, Rio de Janeiro, n. 30, p. 221-238, 2011 b.

LOPES-DAMASIO, L. Para uma abordagem linguístico-discursiva da justaposição oracional: oral e escrito em práticas de letramento. Alfa, São Paulo, v. 60, n. 2, p. 287-317, 2016.

LOPES-DAMASIO, L. R.; SILVA. P. C. S. Causa em aquisição da escrita: processos juntivos. Cadernos de Letras UFF, Niterói, v. 27, n. 55, p. 109-133, 2017.

MARCUSCHI, L. A. Oralidade e escrita. Signótica, v. 8, n. 1, p. 119-145, 1997.

MARCUSCHI, L. A. Letramento e oralidade no contexto das práticas sociais e eventos comunicativos. In: SIGNORINI, I. (org.). Investigando a relação oral/escrito e as teorias do letramento. Campinas: Mercado de Letras, 2001. p. 23-50.

OESTERREICHER, W. Zur Fundierung von Diskurstraditionen. In: HAYE, T.; TOPHINKE, D. (ed.). Gattungen mittelalterlicher schriftlichkeit. Tübingen: Narr, 1997. p. 19-41.

PEKAREK-DOEHLER, S. et al. Configurations paratactiques et grammaire dans l'interaction. In: BÉGUELIN, M. J.; AVANZI, M.; CORMINBOEUF, G. (ed.). La Parataxe. Tome II: Structures, marquages et autres classes de parataxes. Berne: Peter Lang, Collection Sciences pour la communication, 2010. p. 387-340.

RAIBLE, W. Linking clauses. In: HASPELMATH, M. et al. (ed.). Language typology and language universals: an international handbook. Berlin: Walter de Gruyter, 2001. p. 590-617.

SILVA, P. C. S. Processos juntivos de causa em aquisição da escrita: uma abordagem de tradições discursivas. 207 f. 2016. Dissertação (Mestrado em Estudos da Linguagem) - Universidade Federal de Mato Grosso, Cuiabá, 2016.

STREET, B. Perspectivas interculturais sobre o letramento. Filologia e linguística portuguesa, São Paulo, v. 8, p. 465-488, 2006.

THUMM, M. The contextualization of paratatic condicionals. InLiSt, n. 20, p. 1-39, 2000. 
TUÃO-BRITO, A. R. M. Junção e tradições discursivas: uma abordagem no domínio da aquisição de escrita. 159 f. 2014. Dissertação (Mestrado em Estudos da Linguagem) - Universidade Federal de Mato Grosso, Cuiabá, 2014.

ZAVAM, A. S. Por uma abordagem diacrônica dos gêneros do discurso à luz da concepção de tradição discursiva: um estudo com editoriais de jornal. $420 \mathrm{f}$. 2009. Tese (Doutorado) - Universidade Federal do Ceará, Fortaleza, 2009.

Recebido em 18 de setembro de 2018.

Aprovado em 21 de dezembro de 2018. 